\title{
Distribution of air flow around a high-speed train
}

\author{
Saidburkhan Djabbarov* \\ Tashkent State Transport University, Tashkent, Uzbekistan
}

\begin{abstract}
The article presents the results of theoretical studies to establish the nature of the distribution and determine the speed of the air flow formed along a moving high-speed passenger train. In studies, to preserve the geometric similarity, a high-speed train is considered in the form of a bar (or plate) of rectangular cross-section moving in three-dimensional space. To simplify the problem, the movement of a high-speed train at a speed of $160-250 \mathrm{~km} / \mathrm{h}$ in flat terrain, when the height of the embankment is constant, is considered. Assuming that when a high-speed train moves, a turbulent wake is formed, the problem is solved for a turbulent flow using the method of the equivalent heat conduction problem. An equation for the distribution of the layer and along a moving high-speed passenger train is obtained. The results obtained at this stage made it possible to establish the size of the boundary layer and the nature of the change in the distribution of the air flow velocity in its aisles; investigate the impact of secondary air currents generated by high-speed passenger trains on the environment along the high-speed railway.
\end{abstract}

\section{Introduction}

In Japan, China, Korea, the USA, Russia, Germany, France, England, Spain and other countries of Europe conducted experimental and theoretical studies of the aerodynamics of high-speed trains and the related individual questions.

This is, because motion and trains with high speeds occur to change the physics of air flows around the trains, which negatively affect both the dynamics of the train speed and the speed of the railway infrastructure. As the speed of the train increases, the nature and speed of the distribution of air flow around the high-speed train change greatly.

The results of empirical studies using a wind tunnel and a model of trains made it possible to establish the dependence of the magnitude of aerodynamic drag on speed, the shape of the head car and tail of the train, movement conditions (in a tunnel or open area), type of train [1-4].

Theoretical and experimental studies of the interaction of a moving high -speed train with objects located along the railroad tracks and trains, moving along parallel paths (or meet in passing direction) have established minimum safe distance of finding passengers on station platforms to prevent overturning of empty freight cars and containers [5-12].

\footnotetext{
*Corresponding author:_saidhon_@inbox.ru
} 
The results of many years of theoretical and experimental research by C. Baker made it possible to establish and understand the physics of the formation of aerodynamic flows in all parts of a moving high-speed train; ensure the safety and comfort of passengers; to develop measures to reduce the aerodynamic resistance to the movement of the train [1317].

With the diversity and research of the aerodynamics of a high-speed train, the problems of the interaction of high-speed train traffic and the environment, incl. natural, remain unresolved, and a theoretical study of the velocity field around a moving high-speed train is required.

The study of their aerodynamic impact on various objects of the railway infrastructure located near the passing train is becoming more and more relevant for high-speed train traffic.

\section{Methods}

To establish the location (determine the minimum permissible distance of location) of railway infrastructure objects and people (passengers, railway workers), the impact of aerodynamic pressure on them, theoretical studies of the propagation of the velocity field around a high-speed train were carried out.

In reality, a high-speed train can be represented as a diagram shown in figure 1 . The length of a high-speed train consisting of one locomotive and carriages (in the number of $n$ pieces) is as follows

$$
l_{t}=l_{l}+n l_{c}
$$

where $l_{l}$ is the length of the locomotive, $m$;

$l_{c}$ is car length, $m$;

$n$ is the number of cars in the high-speed passenger train, pcs.
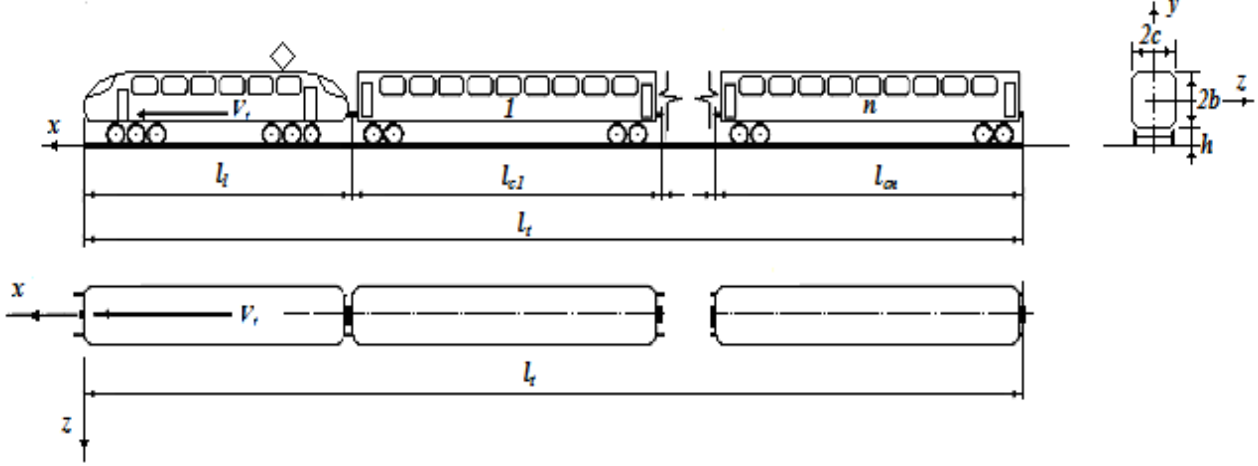

Fig. 1. Passenger train scheme

To preserve the geometric similarity, we represent a high-speed train in the form of a bar or plate of rectangular cross-section with the width $2 c$, height $2 b$, length $l_{t}$ (fig. 2 ), moving in three-dimensional space. To simplify the problem, the process of movement of a high speed train in flat terrain, i.e. when the longitudinal and transverse slopes of the terrain are equal to zero, the height of the embankment is constant. 
Ultimately, the problem reduces to determining the swirl velocity $u$, caused by the high-speed train $u_{p}$ traffic at a rate at some point $N$ with the coordinates $(x, y, z)$.

To identify the nature of the turbulence of the air flow formed along, under and behind a moving high-speed train, the value of the Reynolds number was determined $R_{e}$ using the following formula:

$$
R_{e}=\frac{u_{p} l}{v}
$$

Where $v-$ is air viscosity coefficient, $\mathrm{m}^{2} / \mathrm{s}$.

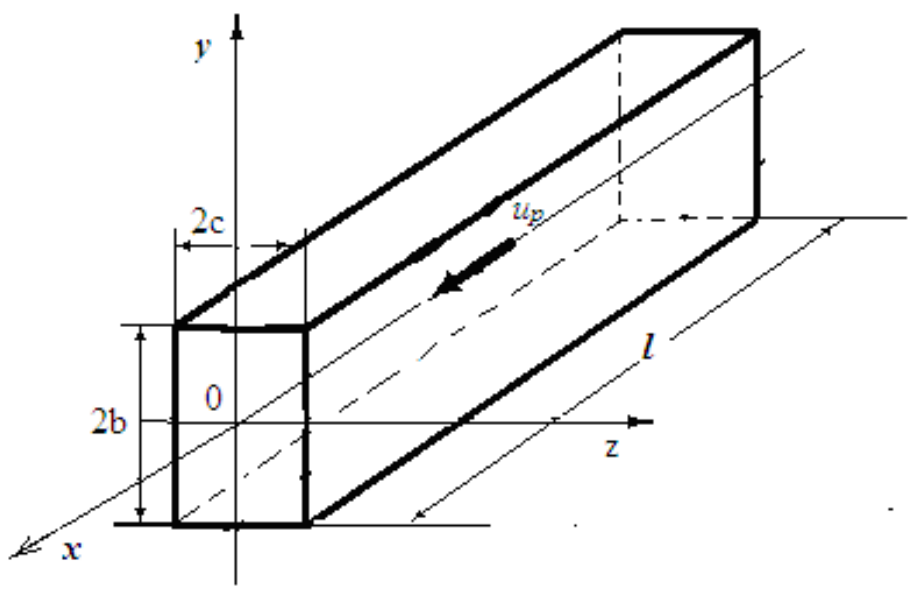

Fig. 2. Estimated train scheme

If we assume that the speed of a high-speed electric train changes in the aisles $V=161-250 \mathrm{~km} / \mathrm{h}$, the length of an electric train consisting of eight cars and two head locomotives is $200 \mathrm{~m}$, i.e. $l=200 \mathrm{~m}$, the value of the viscosity coefficient of air at an ambient temperature of $+40^{\circ} \mathrm{C}$ is $v=1.4 \cdot 10^{-5} \mathrm{~m}^{2} / \mathrm{s}$, then the Reynolds number changes in the following aisles $R_{e}=(6.4-9.9) \cdot 10^{8}$.

Within the specified range of speed and length of an electric train, this problem can be solved for a turbulent flow, assuming a turbulent wake is formed when a high-speed train moves.

For a free turbulent jet, we use the distribution method of the equivalent heat conduction problem [19], according to which the velocity pressure component in the direction of train motion $V^{2}=\rho u^{2}$ (air density in the disturbed region of motion) satisfies the following equation

$$
\frac{\partial V^{2}}{\partial \xi}=\frac{\partial^{2} V^{2}}{\partial \eta^{2}}+\frac{\partial^{2} V^{2}}{\partial \zeta^{2}}
$$

where, $\xi=\xi(x)$ is longitudinal coordinate of fictitious space, where has place equation (1). 
The task of a three-dimensional jet is reduced to finding an experimental connection between physical and fictitious space. Taking from the experiment (for example, on the dependence of the velocity pressure, $\rho u^{2}$ on the jet axis from the distance) this connection, the other two coordinates $\eta$ and $\xi$ should be taken in the first approximation to coincide, respectively, with the coordinates $y$ and $z$.

Equation (1) has a solution in the form of the following integral

$$
V^{2} / V_{p}^{2}=\int_{-\infty}^{+\infty} \int_{-\infty}^{+\infty} f(\eta, \zeta) e^{-\frac{(y-\eta)^{2}+(z-\zeta)^{2}}{4 \cdot \xi}} d \eta d \zeta
$$

Where $V_{p}^{2}=\rho_{0} u_{p}^{2}$ is unperturbed air density;

$f(\eta, \zeta)$ is function characterizing the distribution of the speed pressure at $\xi=0$.

Consider the case of the function representation $f(\eta, \zeta)$ as [18]

$$
\begin{array}{cll}
f(\eta, \zeta)=1 & \text { at } & -b<\eta<b,-c<\zeta<c \\
f(\eta, \zeta) \rightarrow 0 & \text { at } & \eta \rightarrow \infty, \zeta \rightarrow \infty
\end{array}
$$

Then we have:

$$
\bar{V}^{2}(x, y, z)=\frac{V^{2}}{V_{p}^{2}}=\frac{1}{4}\left[\operatorname{erf}\left(\frac{y+b}{2 \sqrt{\xi}}\right)-\operatorname{erf}\left(\frac{y-b}{2 \sqrt{\xi}}\right)\right]\left[\operatorname{erf}\left(\frac{z+l}{2 \sqrt{\xi}}\right)-\operatorname{erf}\left(\frac{z-l}{2 \sqrt{\xi}}\right)\right]
$$

Suppose that the thickness of the boundary layer is known from the experiment $\delta=\delta(x)$, with a fixed value of the variable $z=z_{0}$. We accept it as a change $\xi(x)$ the square of the boundary layer thickness, i.e. we believe $\xi=\delta^{2}(x)$. Then expression (3) establishes the distribution of the velocity head in the plane () at fixed values of the coordinate $Z$

$$
\bar{V}^{2}(x, y, z)=\frac{1}{4}\left[\operatorname{erf}\left(\frac{y+b}{2 \delta(x)}\right)-\operatorname{erf}\left(\frac{y-b}{2 \delta(x)}\right)\right]\left[\operatorname{erf}\left(\frac{z+c}{2 \delta(x)}\right)-\operatorname{erf}\left(\frac{z-c}{2 \delta(x)}\right)\right]
$$

When finding a solution to equation (1), the boundary condition on the earth's surface is not taken into account, where the impermeability condition is satisfied at $y=h$

$$
\frac{\partial \bar{V}_{n}}{\partial y}=0
$$

To satisfy this condition, we use the reflection method, and according to which the solution of equation (1) can be represented in the form 


$$
\left.\stackrel{r}{V}_{n}=\bar{V}(x, y-2 h, z)+\bar{V}(x, 2 h-y, z)\right)
$$

Then it is easy to establish that condition (5) is satisfied by calculating the derivatives of the functions $\bar{V}(x, y-2 h, z)$ and $\bar{V}(x, 2 h-y, z)$ at $y=h$.

$$
\begin{gathered}
\frac{\partial \bar{V}(x,-h, z)}{\partial y}=\frac{g(x, z)}{4 \delta(x) \sqrt{\pi}} \frac{\exp \left[\frac{b-h}{2 \delta(x)}\right]-\exp \left[-\frac{b+h}{2 \delta(x)}\right]}{\sqrt{\operatorname{erf}\left[\frac{b-h}{2 \delta(x)}\right]-\operatorname{erf}\left[-\frac{b+h}{2 \delta(x)}\right]}} \\
\frac{\partial \bar{V}(x, h, z)}{\partial y}=\frac{g(x, z)}{4 \delta(x) \sqrt{\pi}} \frac{-\exp \left[\frac{b-h}{2 \delta(x)}\right]+\exp \left[-\frac{b+h}{2 \delta(x)}\right]}{\sqrt{\operatorname{erf}\left[\frac{b+h}{2 \delta(x)}\right]-\operatorname{erf}\left[-\frac{b-h}{2 \delta(x)}\right]}} \\
g(x, z)=\sqrt{\operatorname{erf}\left[\frac{z+c}{2 \delta(x)}\right]-\operatorname{erf}\left[\frac{z-c}{2 \delta(x)}\right]}
\end{gathered}
$$

Given the equality $\operatorname{erf}(-\varsigma)=-\operatorname{erf}(\varsigma)$, we get

$$
\frac{\partial \bar{V}_{n}(x, h, z)}{\partial y}=\frac{\partial \bar{V}(x,-h, z)}{\partial y}+\frac{\partial \bar{V}(x, h, z)}{\partial y}=0
$$

We choose the dependence of the boundary layer thickness on the coordinate by the formula [20]

$$
\delta=0.37 x\left(\frac{V_{p} x}{v}\right)^{-\frac{1}{5}}
$$

\section{Results and Discussion}

Figure 3 shows the distribution curves of the relative velocity $V / V_{p}$ along the length of the train $z_{0}=0$ for different values of the variable $y$. In calculations, it is accepted: $\rho=\rho_{0} \quad$ (incompressible fluid), $b=c=2 m, \quad h=1 \mathrm{~m}, \quad v=1.4 \cdot 10^{-5} \mathrm{~m}^{2} / \mathrm{s}$, $V_{p}=250 \mathrm{~km} / \mathrm{h}$.

From the analysis of the curves, it follows that the maximum speed of air particles is reached on the roof of the first car, and then, as they approach the tail cars, their speed decreases approximately exponentially with distance. The speed of air particles at the bottom of the cars, both in height (in the variable $y$ ) and in length (in the variable $x$ ), vary insignificantly. 
In fig. 4 shows similar curves at different distances from the side of the cars, where it can be seen that with distance from it, the velocity of air particles located near the roof along the length of the car at the level of the roof of the cars first decreases $(x<120 \mathrm{~m})$ and further, with distance from it, their speed remains practically constant (Fig. 4.a). With distance from the side of the cars, the particle velocities along the length of the car first increase (Fig. 4.b) and then remain constant.

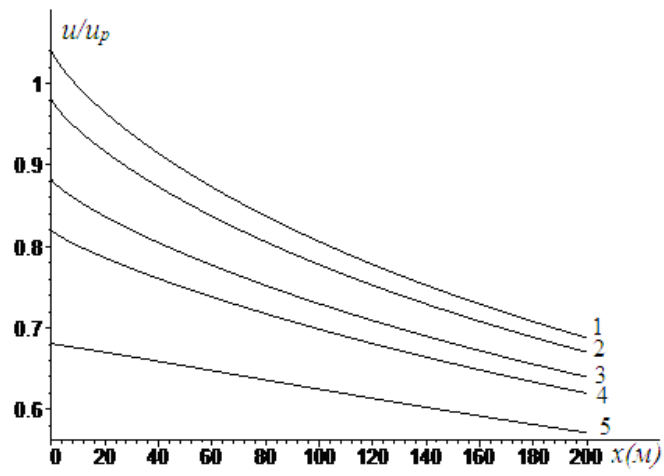

$a$

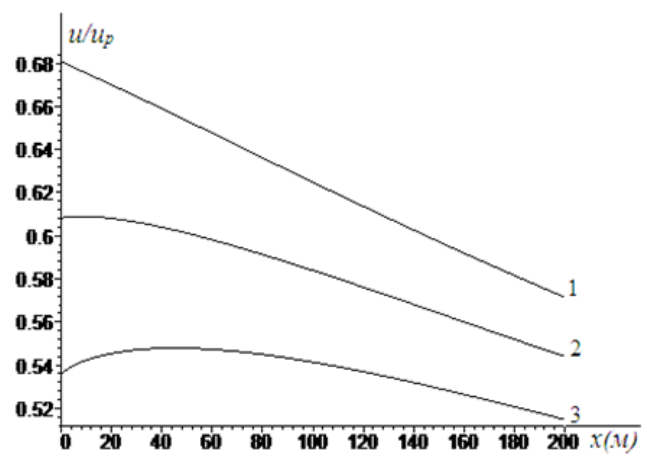

$b$

Fig. 3. Relative air velocity distribution curves $u / u_{p}$ along the length of the car at $z_{0}=0$ and different values of the ordinate $y(M):$ a) over the roof of the wagons: $1 . y=2 m, 2 . y=3.5 m$, $3 . y=4.5 m, 4 . y=5 m, 5 \cdot y=6 m$;

b) at the bottom of the wagons: $1 . y=-2 m, 2 . y=-2.5 m, 3 . y=-3 m$
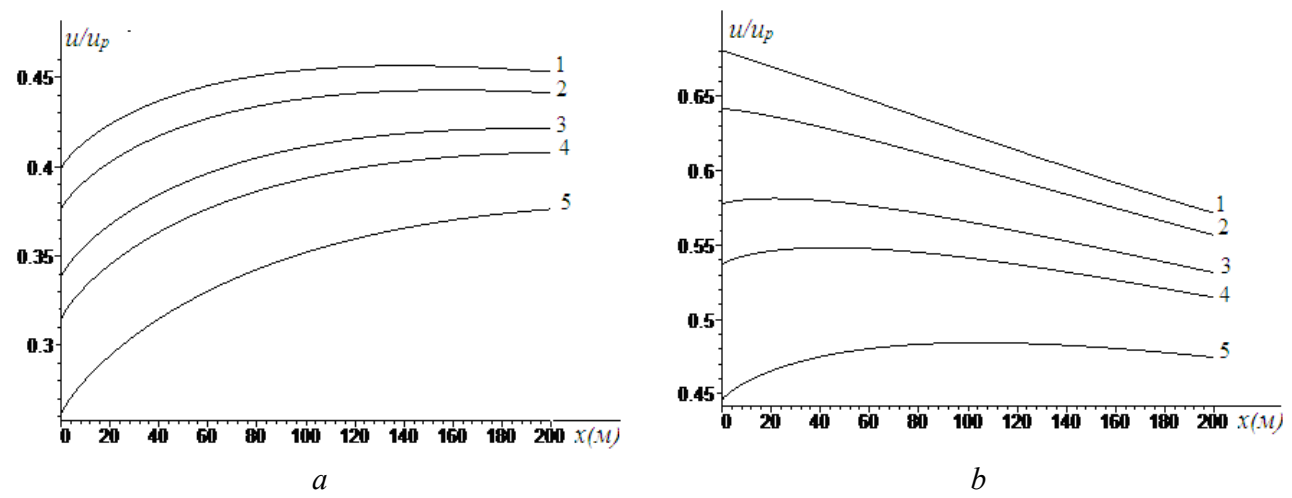

Fig. 4. Distribution curves of the relative air velocity along the length of the car at $z_{0}=4 m$ (a), $z_{0}=6 m(\mathrm{~b})$ and different values of the ordinate $y(m): 1 . y=2 m, 2 . y=3.5 m$, $3 . y=4.5 m, 4 . y=5 m, 5 . y=6 m$.

\section{Conclusions}

The research results obtained at this stage make it possible to establish the size of the boundary layer and the nature of the change in the distribution of the air flow velocity in its 
aisles; to investigate the impact of secondary air currents generated by high-speed passenger trains on the environment along the high-speed rail.

\section{References}

1. Raghu S, Raghunathan H, Kim D, Setoguchi T., Aerodynamics of high-speed railway train, J Progress in Aerospace Sciences 38 pp.469-514, (2002)

2. Derkowski P., Clark S., Sturt R., Aerodynamic effects of high speed trains on passenger, track workers, and other people, Arema (2014)

3. Alexander Orellano. Aerodynamics of High Speed Trains, Vehicle Aerodynamics Lecture Stockholm, KTH, May 12th (2010)

4. Romain B., Pierre-Olivier V., Alex C., Tristan L., Model of High-Speed Train Energy Consumption, International Scholarly and Scientific Research and Innovation 7 (6), (2013)

5. Ben Diedrichs., Studies of Two Aerodynamic Effects on High-Speed Trains: Crosswind Stability and Discomforting Car Body Vibrations Inside Tunnels, Royal Institute of Technology Aeronautical and Vehicle Engineering Rail Vehicles SE- I 00 44 Stockholm.

6. Samuel H., Martin S., Elton T,. HIGH-SPEED PASSENGERAND INTERCITY TRAINAERODYNAMIC COMPUTER MODELING, The International Mechanical Engineering Congress and Exposition, Orlando, Florida, (2000)

7. Robert A., Mac N., Samuel H., Harvey S.L., MEASUREMENT OF THE AERODYNAMIC PRESSURES PRODUCED BY PASSING TRAINS, Proceedings of the ASME / IEEE Joint Rail Conference Washington, DC, April 23-25, (2002)

8. Harvey Shui- Hong Lee., The Aerodynamic Effects of Passing Trains to Surrounding Objects and People, Final Report, DOT-VNTSC-FRA-04-05. US Department of Transportation Research and Special Programs Administration John A. Volpe National Transportation Systems Center, April (2009).

9. Holmes S., Schroeder M., Aerodynamic Effects of High Speed Passenger Trains on Other Trains, Final Report, DOT-VNTSC-FRA-0105, US Department of Transportation Research and Special Programs Administration John A. Volpe National Transportation Systems Center, (2001)

10. Adelya K., Bert B., Wendy J., Jochem S.. CFD simulation of train aerodynamics: train-induced wind conditions at an underground railroad passenger platform, Accepted for publication in Journal of Wind Engineering and Industrial Aerodynamics, January (2015)

11. Djabbarov ST PRESSURE TO RAILWAY INFRASTRUCTURE FROM THE HIGH-SPEED TRAIN MOVEMENT//Conference International Transportation Geotechnics and Geoecology, TGG 2017, Saint Petersburg, Procedia Engineering 189, pp.554 - 559, Russia, (2017)

12. Djabbarov, S., Mirakhmedov, M., Sładkowski, A. Potential and problems of the development of speed traffic on the railways of Uzbekistan 2018 Studies in Systems, Decision and Control 155, pp. 369-421, (2018)

13. Baker C.J., Dalley T., Johnson A., Quinn N.G., The slipstream and wake of a high speed train, Proceedings of the Institution of Mechanical Engineers Part FJournal of Rail and Rapid Transit, 215 (2), pp. 83-99, (2001)

14. Sterling, M., Baker, CJ, Jordon, SC, and Johnson, T., A Study of the Slipstreams of High-Speed Passenger Trains and Freight Trains, Proc. IMechE, Part F: Journal of $\mathrm{r}$ ail and Rapid Transit, 222, pp. 177 - 193, (2008)

15. Baker C.J., The flow around high speed trains, Proceedings of the BBAA VI conference, Milano, Italy, (2008) 
16. Of Baker, by Chris, " T of He Flow Around High Speed Trains," Journal of Wind Engineering and Industrial Aerodynamics, 98, pp. 277 - 299, (2010)

17. Baker C.J., Dalley S.J., Johnson T., Quinn A., and Wright N.G., The Slipstream and Wake of a High-Speed Train, Proc. IMechE, Part F: Journal of Rail and Rapid Transit, 215, pp. 83 - 99, (2001)

18. Jordon S.C., Sterling M., and Baker C.J., Modeling the Response of a Standing Person to the Slipstream Generated by a Passenger Train, Proc. IMechE, Part F: Journal of Rail and Rapid Transit, 223, pp. 567 - 579, (2010)

19. Vulis L.A., Kashkarov V.P., The theory of viscous fluid jets,"Science" p. 422, (1965)

20. Schlichting G., Theory of the boundary layer. M. "Science", p.712, (1974) 